\title{
EFEITO DE BACTÉRIAS RIZOSFÉRICAS SOBRE O DESENVOLVIMENTO DA CENOURA
}

Dora Inés KOZUSNY-ANDREANI ${ }^{1}$

Julio César AGIADO

Roberto ANDREANI JUNIOR ${ }^{3}$

\begin{abstract}
${ }^{1}$ Licenciada em Genética, Doutora, Professora Titular do Curso de Agronomia - Laboratório de Microbiologia Universidade Camilo Castelo Branco (Unicastelo) Campus Fernandópolis, SP. doraines@ terra.com.br ${ }^{2}$ Graduado em Agronomia, Universidade Camilo Castelo Branco, Campus Fernandópolis, SP. julio.agiado@plantar.com.br

${ }^{3}$ Engenheiro Agrônomo, Doutor, Professor Titular do Curso de Agronomia - Universidade Camilo Castelo Branco (Unicastelo) Campus Fernandópolis, SP. robertoandreani@uol.com.br
\end{abstract}

\section{Recebido em: 23/05/2014 - Aprovado em: 30/06/2014 - Disponibilizado em: 30/07/2014}

RESUMO:O objetivo deste trabalho foi avaliar as bactérias rizosféricas, isoladas de Crotalaria spectabilis Roth , sobre o desenvolvimento e produtividade da cenoura cv Nantes. Sementes de cenoura foram bacterizadas por meio da imersão em suspensões bacterianas padronizadas, por cinco minutos. As sementes inoculadas foram, então, depositadas em vasos com terra misturada com vermiculita (3: 1). O experimento foi conduzido em condições de casa de vegetação por 90 dias, quando se procedeu à colheita de plantas. Foi avaliada a fitomassa fresca e seca da parte aérea e da raiz, diâmetro e comprimento da raiz, acúmulo de nitrogênio, fósforo e potássio nas raízes. Verificou-se que a maioria das rizobactérias apresentaram efeitos benéficos sobre o desenvolvimento da cenoura.

Palavras-chave: Daucus carota L. Crotalaria spectabilis Roth. Rizobactérias. Promoção do crescimento vegetal. Produtividade.

\section{EFFECT OF RHIZOSPHERE BACTERIA ON THE DEVELOPMENT OF CARROT}

\begin{abstract}
The aim of this work was to evaluate rhizosphere bacteria, isolated from Crotalaria spectabilis, on the development and productivity of carrot cv Nantes. Carrot seeds were bacterized through immersion in standardized suspensions of the isolated, for five minutes. The inoculated seeds were then deposited in pots containing earth mixed with vermiculite (3: 1). The experiment was conducted in greenhouse conditions for 90 days when it proceeded to harvest of plants. It was assessed the fresh and dry phytomass of the aerial part and of the root, diameter and length of the root, accumulation of nitrogen, phosphorus and potassium in the roots. It was found that most of the rhizobacteria have beneficial effects on the development of the carrot.
\end{abstract}

Key words: Daucus carota L. Crotalaria spectabilis Roth. Rhizobactérias. Promoting plant growth. Productivity.

\section{INTRODUÇÃO}

A cenoura (Daucus carota L.) é uma importante hortaliça do grupo das raízes tuberosas cultivadas em todo o país. Trata-se de uma hortaliça de grande aceitação pela excelente palatabilidade e alto conteúdo de pró-vitamina A ou caroteno. Além disso, a boa conservação pós-colheita permite que seja produzida em locais distantes dos grandes centros consumidores. Estes fatores, aliados à 
introdução de novas tecnologias de produção adaptadas às condições edafoclimáticas das diferentes regiões brasileiras contribuíram para que nas últimas décadas houve-se grande expansão da cultura (FINGER, et al., 2005).

As rizobactérias, conhecidas como promotoras do crescimento de plantas (PGPR) são benéficas às plantas por promoverem seu desenvolvimento devido à produção de fitormônios, a mobilização fosfato, a produção de sideróforos e antibióticos, a inibição na planta da síntese de etileno e indução nas plantas a resistência sistêmica a patógenos (VAFADAR et al. 2014), oxidação do enxofre e aumento da permeabilidade das raízes (MARIANO e KLOEPPER, 2000). Entre as PGPR, as bactérias solubilizadoras de fosfatos e as fixadoras de nitrogênio atmosférico são importantes para plantas cultivadas, pois aumentam a absorção de nitrogênio e de fósforo, desempenhando um papel crucial como biofertilizantes (SINGH et al., 2011, 2012)

As rizobactérias atuam indiretamente como agentes de controle biológico de doenças, pela competição por nutrientes com o patógeno, produção de sideróforos e antibióticos (RAMAMOORTHY et al., 2001), e pela resistência induzida (NANDAKUMAR et al, 2001).

Os benefícios das PGPR foram observados em diferentes espécies vegetais, como abóbora (CHEN et al., 2000), beterraba (THRANE et al., 2000), rabanete (LEEMAN et al, 1995), berinjela (KUMAR, 1998), batata, alface (GOMES et al., 2003; SOTTERO et al., 2006; SCHLINDWEIN et al., 2008). O objetivo do presente trabalho foi avaliar o efeito de rizobactérias isoladas de Crotalária spectabilis Roth sobre o desenvolvimento de cenoura (Daucus carota L) cv. Nantes.

\section{MATERIAL E MÉTODOS}

O presente estudo foi realizado na Universidade Camilo Castelo Branco UNICASTELO, Campus de Fernandópolis SP, localizado nas coordenadas geográficas latitude $20^{\circ} 17^{\prime} 39^{\prime \prime}$ Sul, longitude 50¹6'55' Oeste e altitude de 504 metros.

As sementes utilizadas no experimento foram da espécie Daucus carota L cv. Nantes, registradas como tolerantes ao ataque de nematóides, apresentando germinação de $90 \%$ e pureza física de $99 \%$, e o valor cultural de $89,1 \%$.

Utilizou-se um substrato constituído de uma mistura de $75 \%$ de solo coletado na horta da Universidade e $25 \%$ de vermiculita, estes componentes foram homogeneizados antes do preenchimento dos vasos de PVC, com capacidade de 20L.

O delineamento experimental empregado foi o inteiramente casualizado, com quatro repetições e quinze tratamentos, constituídos por uma testemunha onde as sementes foram imersas por cinco minutos em uma solução líquida composta de meio TSB (triptecaseina soja), e 14 tratamentos com inoculação com as diferentes estirpes de 
rizobactérias isoladas da rizosfera de Crotalária spectabilis, denominadas UCCBjCE 01, UCCBj-CE 02, UCCBj-CE 04, UCCBj-CE 05, UCCBj-CE 06, UCCBj-CE 07, UCCBj-CE 11, UCCBj-CE 13, UCCBjCE 14, UCCBj-CE 16, UCCBj-CE 17, UCCBj-CE 18 UCCBj-CE 19; UCCBj-CE 20.

Para preparação dos inoculantes as bactérias foram cultivadas em meio TSB por um período de 72 horas a $36^{\circ} \mathrm{C}$ e sob agitação a 200rpm, após este período a concentração bacteriana foi aferida para $10^{8}$ UFC (unidades formadoras de colônias). As sementes permaneceram em contato com o inoculante por 5minutos, e em seguida com o auxílio de pinça estéril, estas foram semeadas.

Após emergência das plântulas foi realizado raleio, deixando uma por vaso, em seguida foram adicionados $200 \mathrm{~mL}$ de solução nutritiva Norris e Dobereiner: $\mathrm{KCl} 2 \mathrm{mM}$; $\mathrm{K}_{2} \mathrm{HPO}_{4} \quad 0,3 \mathrm{nM} ; \mathrm{KH}_{2} \mathrm{PO}_{4}$ 0,7Mm; $\mathrm{CaSO}_{4}$. $5 \mathrm{H}_{2} \mathrm{O} 0,3 \mu \mathrm{M} ; \mathrm{ZnSO}_{4} .7 \mathrm{H}_{2} \mathrm{O} 0,7 \mu \mathrm{M} ; \mathrm{MnSO} 4$ $1 \mu \mathrm{M} ;\left(\mathrm{NH}_{4}\right) 6 \mathrm{Mo}_{7} \mathrm{O}_{24} 0,002 \mu \mathrm{M} ; \mathrm{H}_{3} \mathrm{BO}_{3} 11,5$ $\mu \mathrm{M} ; \mathrm{Fe} \mathrm{SO}_{4} .7 \mathrm{H}_{2} \mathrm{O} \quad 17,9 \mu \mathrm{M}$; ácido cítrico 26 $\mu \mathrm{M}$. A testemunha recebeu também de $50 \mathrm{~mL}$ de solução de nitrato de potássio $(1,0 \% \mathrm{~m} / \mathrm{v})$. A irrigação foi realizada, diariamente, com 100 mL água deionizada.

A colheita foi realizada 90 dias após a semeadura, as plantas foram lavadas cuidadosamente e o excedente de água foi retirado com papel toalha e posteriormente foram avaliados os seguintes parâmetros: fitomassa fresca da raiz e da parte aérea, diâmetro e comprimento da raiz, comprimento da parte aérea. Após avaliação destes parâmetros as raízes foram submetidas a temperatura de $56^{\circ} \mathrm{C}$ por 96 horas, em estufa com circulação de ar forçado quando se verificou o peso constante das amostras, estas foram avaliadas quanto a fitomassa seca da raiz e parte aérea. Seguidamente as amostras foram enviadas ao laboratório de Analises de Solo e de Plantas Micellium (Barretos, SP) para obtenção da concentração de $\mathrm{N}$ total, fósforo e potássio.

Os dados obtidos foram tabulados para análise de resultados pelo teste $\mathrm{F}$ na análise da variância e as médias comparadas pelo teste de Tukey com $5 \%$ de probabilidade, utilizando o "software" SAS- Statistical Analyses System - SAS.

\section{RESULTADOS E DISCUSÃO}

Os resultados da fitomassa fresca da parte aérea de plantas de cenoura estão apresentados na figura 1. Verificou-se que não houve diferenças significativas entre os tratamentos, exceto aquele que recebeu inoculação com a estirpe UCCBj-CE14 que apresentou menor acúmulo de fitomassa e diferiu do tratamento UCCBj-CE 05. Estes resultados são semelhantes aos obtidos por Gasoni et al. (2001), que obtiveram aumentos significativos na massa fresca de alface inoculada com rizobactérias. $\mathrm{O}$ incremento verificado na fitomassa fresca da parte aérea da cenoura poderia ser atribuído à eficiência da interação planta-bactéria na região da raiz, 
pois as rizobactérias aumentam da disponibilidade de nutrientes pela fixação de nitrogênio atmosférico ou solubilização do fosfato, oxidação do enxofre e aumentam da permeabilidade das raízes (CHABOT et al.; 1996; ANTOUN et al., 1998; MARIANO e KLOEPPER, 2000).

Figura 1: Valores médios da fitomassa fresca da parte aérea $\left(\mathrm{g}_{\text {planta }}{ }^{-1}\right)$ de cenoura cv Nantes inoculadas com estirpes isoladas de rizosfera de Crotalaria spectabilis.

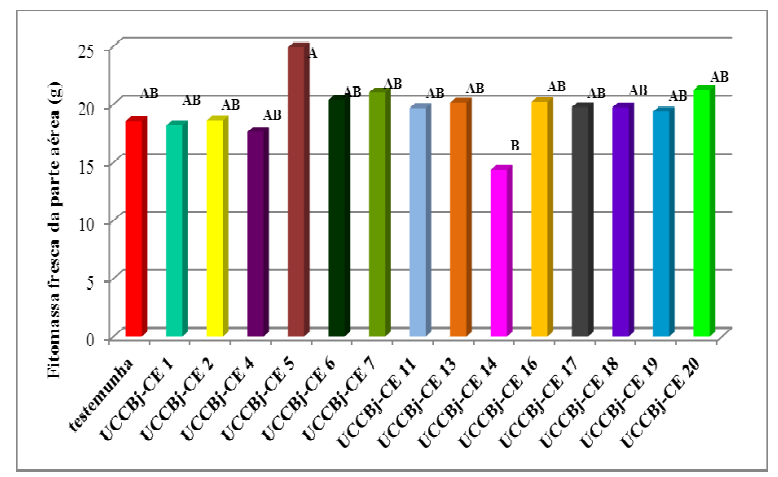

Fonte- Universidade Camilo Castelo Branco, campus Fernandópolis. 2014.

O comprimento das raízes de cenoura foi influenciado pela inoculação com as bactérias UCCBj-CE 01, UCCBj-CE 06, U CCBj-CE 11, UCCBj-CE 14, UCCBj-CE 16, e UCCBj-CE 18 que apresentaram maior comprimento inclusive que a testemunha que recebeu nitrogênio mineral (figura 2). As demais bactérias também influenciaram positivamente no crescimento longitudinal das raízes, exceto UCCBj-CE 18 e UCCBjCE 19 que apresentaram comprimento semelhante à testemunha. Estes resultados provavelmente estão relacionados com a produção ou a alteração dos níveis de fitormônios pelos micro-organismos, principalmente ácido indolacético (AIA), liberado na rizosfera pelas bactérias epifíticas e colonizadoras de tecidos vegetais (LINDOW e BRANDL, 2003) e giberelinas (YANNI et al., 2001). Provavelmente as bactérias UCCBj-CE 01, UCCBj-CE 06, U CCBj-CE 11, UCCBj-CE 14, UCCBj-CE 16, e UCCBj-CE 18 são produtoras de fitormônios que favoreceram no alongamento das raízes.

Figura 2: Comprimento das raízes $\left(\mathrm{cm} \mathrm{planta}^{-1}\right)$ de cenoura cv Nantes inoculadas com estirpes isoladas de rizosfera de Crotalaria spectabilis.

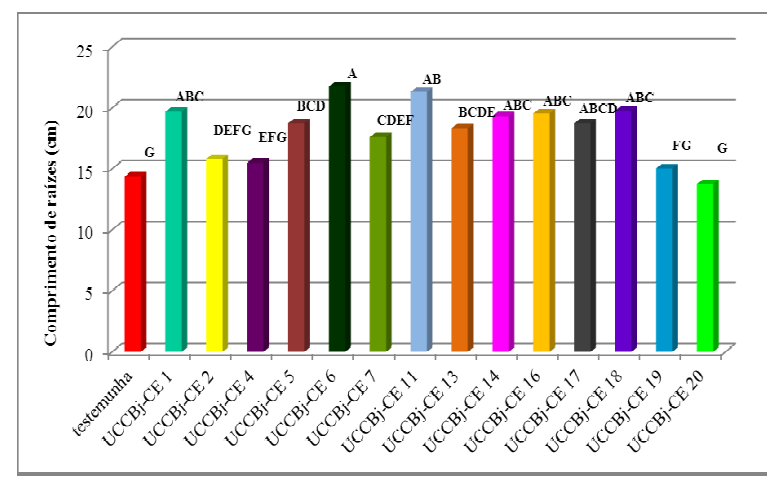

Fonte- Universidade Camilo Castelo Branco, campus Fernandópolis. 2014.

O perímetro basal das raízes, nas plantas inoculadas com UCCBj-CE 04, UCCBj-CE 13, UCCBj-CE 18 , foi superior à maioria dos tratamentos (figura 3). No entanto as plantas inoculadas com UCCBj-CE 13 não diferiram estatisticamente dos demais tratamentos exceto da testemunha que apresentou menor perímetro radicular. 
Figura 3: Perímetro de raízes $(\mathrm{cm})$ de cenoura cv Nantes inoculadas com estirpes isoladas de rizosfera de Crotalaria spectabilis.

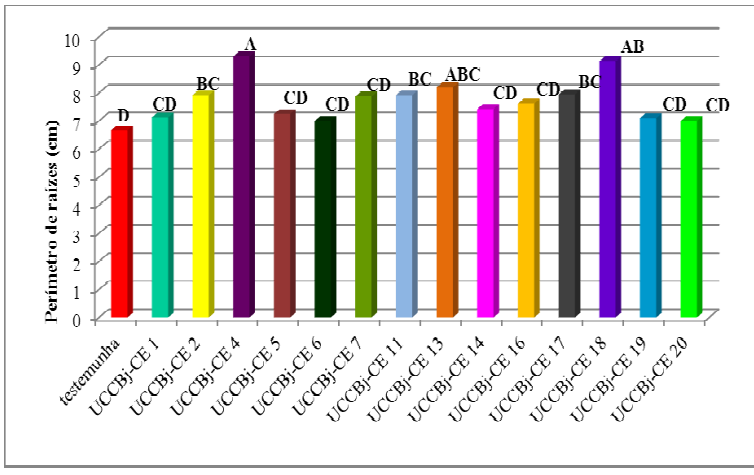

Fonte: Universidade Camilo Castelo Branco, campus Fernandópolis. 2014.

Os melhores resultados para produtividade (fitomassa fresca) da cenoura verificou-se nas plantas inoculadas com UCCBj-CE 01, UCCBj-CE 04, UCCBj-CE 06, UCCBj-CE 11, UCCBj-CE 14, UCCBjCE 17, UCCBj-CE 18, não havendo diferenças entre elas, porem diferiram das plantas que receberam nitrogênio na forma de nitrato de potássio (figura 4). A produtividade nos demais tratamentos foi semelhante à obtida pela testemunha. Sabe-se que o êxito da inoculação com rizobactérias depende da capacidade das cepas para competir com a microflora nativa livre do solo, sobrevivendo e proliferarando antes que se forme a raiz e depois, de colonizar a raiz, devem competir com as bactérias rizosféricas pelos exudatos (BACILIO-JIMÉNEZ et al., 2001; KOSDROJ et al., 2004). Levando em consideração a produtividade da cenoura, pode se afirmar que as estirpes de rizobactérias UCCBj-CE 01, UCCBj-CE 04, UCCBj-CE 06, UCCBj-CE 11, UCCBj-CE
14, UCCBj-CE 17, UCCBj-CE 18, utilizadas neste experimento foram mais competitivas em colonizar as raízes que as bactérias presentes no substrato e apresentaram características de promotoras de crescimento das plantas de cenoura

As variações na colonização das raízes pelas rizobactérias em condições controladas podem ser atribuídas também, à umidade do substrato, (REIS JUNIOR et al., 2004); distribuição das bactérias sobre a raiz, sendo que as zonas de maior crescimento produzem mais exsudatos favorecendo a colonização (FISCHER et al., 2000); a especificidade cepa-hospedeiro (SHULZE e POSCHEL, 2004); e a competitividade com as bactérias nativas (SAUBIDET et al., 2002).

Figura 4: Valores médios da fitomassa fresca das raízes (g planta ${ }^{-1}$ ) de cenoura cv Nantes inoculadas com estirpes isoladas de rizosfera de Crotalaria spectabilis.

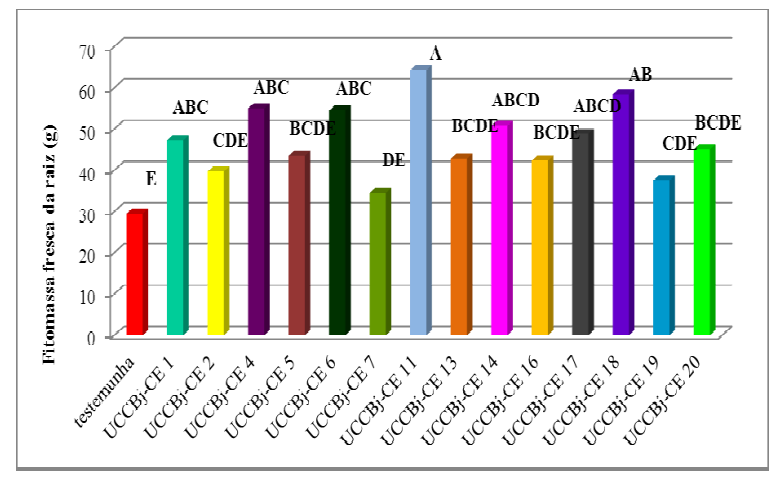

Fonte: Universidade Camilo Castelo Branco, campus Fernandópolis. 2014.

O acúmulo de fitomassa seca está apresentado na figura 5. Verificou-se menor fitomassa seca nos tratamentos testemunha e UCCBj-CE 07 que diferiram de UCCBj-CE 04, UCCBj-CE 11, UCCBj-CE 17 e UCCBj- 
CE 18. Os demais tratamentos apresentaram resultados variáveis. Estes resultados mostram o potencial destas quatro estirpes na produtividade da cenoura cv Nantes. Os benefícios das PGPR foram observados em diferentes espécies de hortaliças (CHEN et al., 2000, THRANE et al., 2000, SOTTERO et al., 2006; SCHLINDWEIN et al., 2008), e em plantas perenes, como café e citrus (FREITAS e AGUILAR VILDOSO, 2004).

Figura 5: Valores médios da fitomassa seca de raízes $\left(\right.$ g planta $\left.^{-1}\right)$ de cenoura cv Nantes inoculadas com estirpes isoladas de rizosfera de Crotalaria spectabilis.

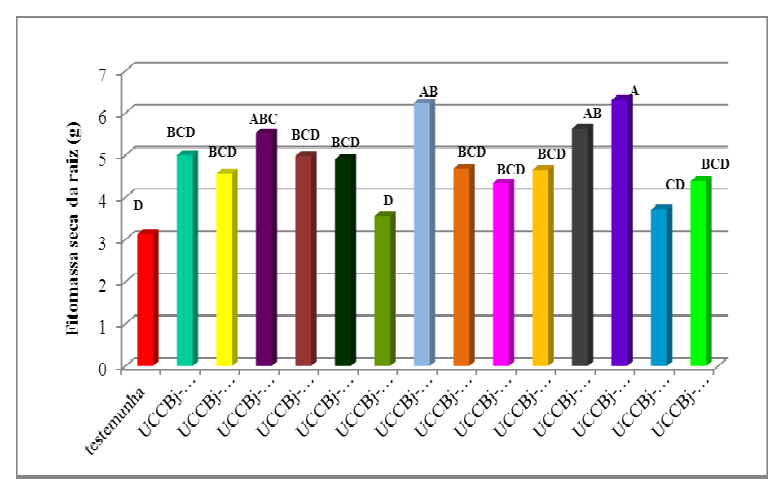

Fonte: Universidade Camilo Castelo Branco, campus Fernandópolis. 2014.

A analise de tecidos vegetais é uma medida direta da disponibilidade de nutrientes no substrato de cultivo, pois os nutrientes nos tecidos vegetais correspondem à quantidade de nutriente absorvida pelas plantas. Desta forma o teor de nutrientes nos tecidos vegetais reflete a real disponibilidade, pois existe uma relação entre o fornecimento de um nutriente pelo substrato de cultivo ou por um fertilizante e a concentração nas folhas, e uma relação entre essa concentração e a produtividade da cultura (BERNARDI et al.,
2005). Segundo Pazos e Hernández (2001) o incremento da massa das plantas, quando inoculadas com bactérias, pode ser creditado a uma eficiente interação planta-bactéria na região da raiz, pois as rizobactérias provocam estímulos ao desenvolvimento do sistema radicular, com aumento dos pelos radiculares, que por sua vez, produz uma maior absorção de água e nutrientes.

A figura 6 mostra os teores de fósforo nas raízes de cenoura. Verificou-se que na maioria na maioria dos tratamentos este parâmetro foi elevado, exceto na testemunha e nas plantas inoculadas com UCCBj-CE 01, UCCBj-CE 02, UCCBj-CE 14, UCCBj-CE 19 e UCCBj-CE 20 que apresentaram menor acúmulo do nutriente. Os resultados obtidos permitem supor que as bactérias que aumentaram o teor de fósforo nas raízes provavelmente estejam relacionadas a uma eficiente interação micro-organismos - planta ou à habilidade de solubilização de fosfatos pelas bactérias (MARIANO e KLOEPPER, 2000).

Figura 6: Teores de fósforo $\left(\mathrm{g} \mathrm{kg}^{-1}\right)$ em raízes de cenoura cv Nantes inoculadas com estirpes isoladas de rizosfera de Crotalaria spectabilis.

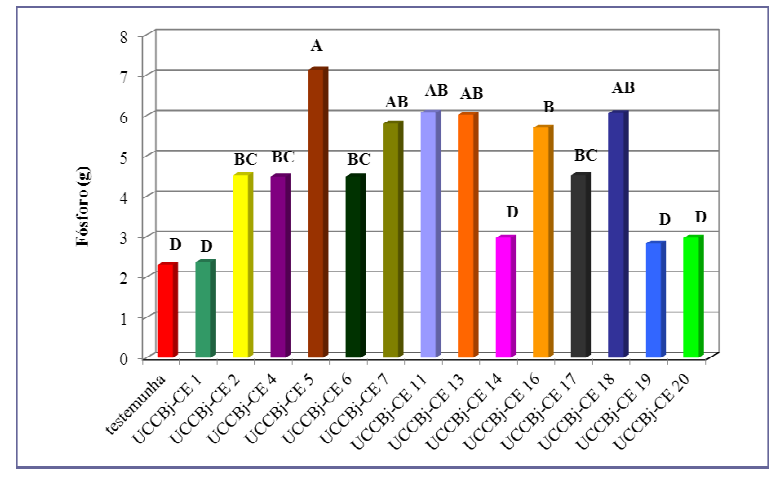

Fonte: Universidade Camilo Castelo Branco, campus Fernandópolis. 2014. 
Na figura 7 estão apresentados os teores de potássio. Verificou-se que os tratamentos inoculados com as rizobactérias UCCBj-CE 04, UCCBj-CE 05, UCCBj-CE 06, UCCBjCE 07, UCCBj-CE 11, UCCBj-CE 13, UCCBj-CE 16, UCCBj-CE 17 e UCCBj-CE 18 apresentaram maior teor de potássio nas raízes, mostrando que houve interação entre as bactérias e as plantas cenoura. As rizobactérias promotoras do crescimento vegetal apresentam vários mecanismos que beneficiam o desenvolvimento das plantas. A promoção do crescimento pode ser de forma direta pela produção de fitohormônios e aumento da disponibildade de nutrientes pela fixação de nitrogênio atmosférico ou solubilização do fosfato, oxidação do enxofre e aumento da permeabilidade das raízes (VAFADAR et al., 2014, MARIANO e KLOEPPER, 2000), no entanto não há referências quanto ao potássio (GOMES et al., 2003).

Figura 7: Teores de Potássio $\left(\mathrm{g} \mathrm{kg}^{-1}\right)$ em raízes de cenoura cv Nantes inoculadas com estirpes isoladas de rizosfera de Crotalaria spectabilis.

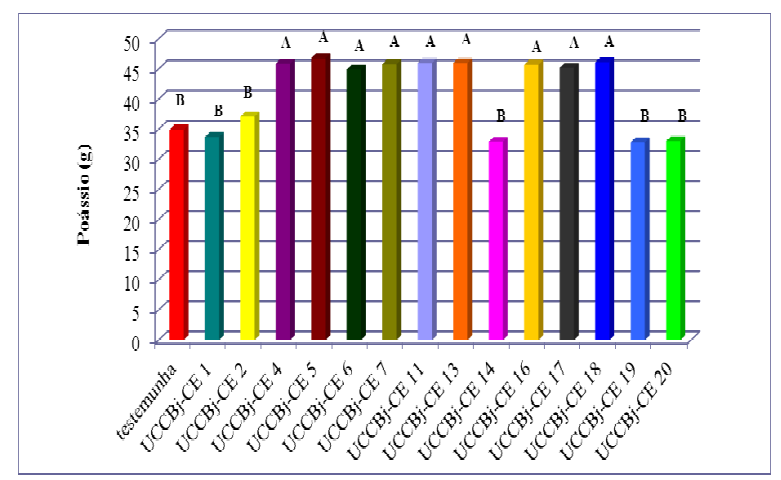

Fonte: Universidade Camilo Castelo Branco, campus Fernandópolis. 2014.
Os maiores acúmulos de nitrogênio nas raízes de cenoura foram induzidas pelas bactérias UCCBj-CE 4, UCCbj-CE 11, e UCCBj-CE 18 que diferiram significativamente da testemunha que recebeu nitrato de potássio como fonte de $\mathrm{N}$ (figura 8). No entanto, verificou-se que a maioria das bactérias utilizadas induziram o favoreceram para o acúmulo de nitrogênio nas raízes de cenoura, exceto UCCBj-CE 2 e UCCBj-CE 7 que não apresentaram os resultados esperados, sendo estes $37,5 \%$ e $38,52 \%$, respectivamente, inferiores a $\mathrm{UCCBj}-\mathrm{CE} 11$ com valores médios de $\mathrm{N}$ de $6,9 \mathrm{~g} \mathrm{~kg}^{-1}$. A promoção do crescimento de plantas como conseqüência das interações rizosféricas poderia ser devida à fixação do nitrogênio atmosférico (ANTOUN e PREVOST, 2005).

Figura 8: Teores de Nitrogênio $\left(\mathrm{g} \mathrm{kg}^{-1}\right)$ em raízes de cenoura cv Nantes inoculadas com estirpes isoladas de rizosfera de Crotalaria spectabilis.

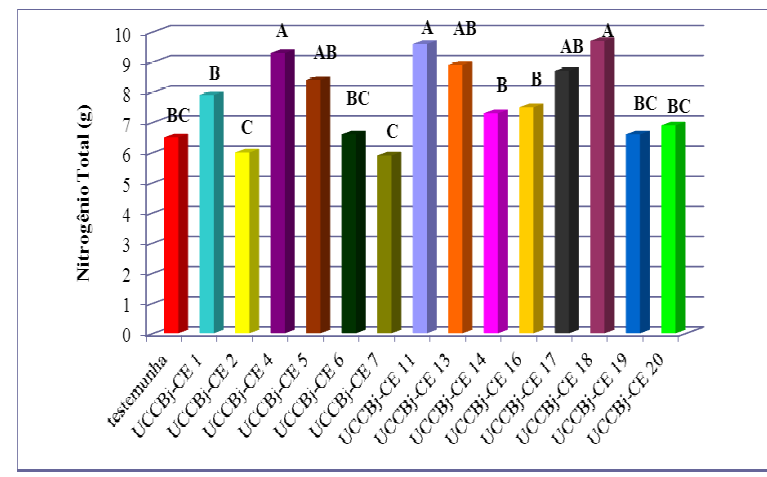

Fonte: Universidade Camilo Castelo Branco, campus Fernandópolis. 2014.

É possível afirmar que a das bactérias utilizadas na apresentaram especificidade cepa-hospedeiro já que as mesmas foram 
isoladas da rizosfera de Crotalaria spectabilis, no entanto foram capazes de promover o crescimento de plantas de cenoura. Novos ensaios deverão ser realizados em condições de campo.

\section{CONCLUSÕES}

Pelos resultados obtidos conclui-se que as rizobacterias UCCBj-CE 04, UCCBj-CE 11, UCCBj-CE 17 e UCCBj-CE 18 induziram a maior produtividade da cenoura cv Nantes, evidenciando potencial como promotoras do crescimento vegetal.

\section{REFERÊNCIAS}

ANTOUN, H., PREVOST, D. Ecology of plant growth promoting rhizobacteria. In: Siddiqui, Z.A. (Ed.), PGPR: Biocontrol and Biofertilization. Springer, Dordrecht, 2005. pp. 1-38.

\section{BACILIO-JIMENEZ, M.; AGUILAR-}

FLORES, S.; DEL VALLE, M.M.; PEREZ, A.; ZEPEDA, A.; ZENTENO, E. A

Endophytic bacteria in rice seeds inhibit early colonization roots by Azospirillum brasilense.

Soil Biology and Biochemical, v.33, p.167172, 2001.

BERNARDI, A.C.C.; VERRUMABERNARDI, M.R.; WERNECK, C.G.; HAIM, P.G.; MONTE, M.B.M. Produção, aparência e teores de nitrogênio, fósforo e potássio em alface cultivada em substrato com zeólita. Horticultura Brasileira, v.23, n.4, p. 920-924, 2005.

CHEN C; BÉLANGER, RR; BENHAMOU N; PAULITZ TC. Defense enzymes induced in cucumber roots by treatment with plant growth-promoting rhizobacteria (PGPR) and pythium sphsnidermstum. Physiology and Molecular Plant Pathology, v.56, p:1323.2000.

FINGER, F.L.; DIAS, D.C.F. dos S.; PUIATTI, M. Cultura da cenoura. In; PAULO CEZAR REZENDE FONTES. Olericultura teoria e prática. Viçosa, MG, 2005. p.371384.

FISCHER, S.; RIVAROLA, V.; MORI, G. Colonization of wheat by Azospirillum brasilense is impaired by saline stress. Plant and soil, v. 225, p.187-191, 2000.

GASONI, L.; COZZI, J.; KOBAYASHI, K.; YOSSEN, V.; ZUMELZÚ, G.; BABBITT, S.; KAHN, N. Yeld response of lettuce and potato to bac terial and fungal inoculants under field conditions in Cordoba. Journal of plant deseases and protection, v.108, n.5, p. 530-535, 2001.

GOMES, A.M.A.; MARIANO, R.L.;

SILVEIRA, E.B.; MESQUITA, J.C.P.

Isolamento, seleção de bactérias e efeito de

Bacillus spp. na produção de mudas orgânicas 
de alface. Horticultura Brasileira, v.21, n.4, 699-703, 2003.

KOZDROJ. J.; TREVOS, J.T.; VAN ELSAS, J.D. Influence of introduced potencial biocontrol agents on maize seedling growth and bacterial community structure in the rizosphere. Soil Biology and Biochemestry, v.36,p.1775-1784, 2004.

KUMAR, B.S.D. Disease suppression and crop improvement through fluorescens pseudomonads isolated from cultivated soils.

World Journal of Microbiology and Biotechnology, v.14, p:735-741. 1998.

LEEMAN S; D.E.N.; OUDEN, F.M.; VAN PELT, J.A.; DIRKX, F.P.M.; STEIJL, H. Iron availability affects induction of systemic resistence to Fusarium wilt of radish by Pseudomonas fluorescens. Phytopathology, v. 86, p:149-155. 1995.

LINDOW, S.E.; BRANDL, M.T. Microbiology of de Phyllosphere. Applied and Environmental Microbiology, v.69, p.18875-1883, 2003.

MARIANO, R.L.R.; KLOEPPER, J.W.

Método alternative de biocontrole: resistência sistêmica induzida por rizobactérias. Revisão Anual de Patologia de Plantas, v.8, p.121137, 2000.

MARIANO, R.L.R.; SILVEIRA, E.B.; ASSIS, S.M.P.; GOMES, A.M.A.;
NASCIMENTO, A.R.P.; DONATO,

V.M.T.S. Importância de bactérias

promotoras de crescimento e biocontrole de doenças de plantas para uma agricultura sustentável. Anais da Academia Pernambucana de Ciência Agronômica, v.1, p.89-111, 2004.

MOREIRA, F.M.S.; SIQUEIRA, J.O.

Microbiologia e Bioquímica do Solo.

Editora UFLA, $2^{\text {a }}$ ed., 2006, 729p.

NANDAKUMAR, R.; BABU, S.;

VISWANATHAN, R.; RAGUCHANDER, T.; SAMIYAPPAN, R. Induction of systemic resistance in rice against sheath blight disease by Psudomonas fluorescens. Soil Biology and Biochemical, v:33 p.603-612, 2001.

PAZOS, M. HERNANDEZ, A. Evaluación de cepas nativas del género Azospirillum y su interacción con el cultivo de arroz. Cultivos Tropicales, v.22, n.4,p. 25-28, 2001.

RAMAMOORTHY, V.; VISWANATHAN, R.; RAGUCHANDER, T.; PRACKASAM, V.; SAMIYAPPAN, R. Induction of systemic resistance by plant growth promoting rhizobacteria $\mathrm{n}$ crop plants against pests and diseases. Crop Protection, v.20, p.1-20, 2001.

REIS JUNIOR, F.B.; SILVA, M.F.; TEIXEIRA, K.R.S.; URQUIAGA, S.; REIS. V.M. Identification of Azospirillum amazonense isolated to Brachiaria spp at 
differents stages and growth conditions and bacterial plants hormone production. Revista

Brasileira de Ciência do Solo, v.28, p.103-

113, 2004.

SAUBIDET, M.; FATTA, N.; BARNEIX,

A.J. The effect of inoculation with

Azospirillum brasilense on growth and

nitrogen utilization by wheat plants. Plant

and Soil, v.245, p.215-222, 2002

SCHLINDWEIN, G.; VARGAS, L.K.;

LISBOA, B.B.; AZAMBUJA, A.C.;

GRANADA, C.E.; GABIATTI, N.C.;

PRATES, F.; STUMPF, R. Influência da

inoculação de rizóbios sobre a germinação e o

vigor de plântulas de alface. Ciência Rural,

v.38, p.658-664, 2008.

SCHULZE J; POLSCHEL G. Bacterial

inoculation of maize affects carbon allocation

to roots and carbon allocation to roots

turnover in the rhizosphere. Plant and Soil,

v.267, p.235-241, 2004.

SINGH, J.S.; PANDEY, V.C.; SINGH, D.P.

Efficient soil microorganisms: a new

dimension for sustainable agriculture and

environmental development. Agric

Ecosystems Environ., v. 140, p.339-353,

2011. organic field conditions. Mycorrhiza, v.23, n.1, p.5-44, 2012.

SOTTERO, N.A.; FREITAS, S.S.; MELO,

A.M.T.; TRANI, P.E.. Rizobactérias e alface:

colonização rizosférica, promoção de

crescimento e controle biológico. Revista

Brasileira de Ciência do Solo, v.30, p:225-

234. 2006.

VAFADAR, F.; AMOOAGHAIE, R.;

OTROSHY, M. Effects of plant-growth-

promoting rhizobacteria and arbuscular

mycorrhizal fungus on plant growth,

stevioside, NPK, and chlorophyll content of

Stevia rebaudiana, Journal of Plant

Interactions, v.9, n.1, p.128-136, 2014

YANNI, Y.; RIZKABD EL-FATTAH, Y.;

SQUARTINI, A.; CORICH, V.;

GIACOMINI, A.; DE BRUIJN, F.;

RADEMAKER, J. ; MAYA-FLORES, J. ;

OSTROM, P.; VEGA-HERNANDEZ, M.

The beneficial plant growth-promoting association of Rhizobium leguminosarum bv.

Trifolli with rice roots. Australian Journal of

Plant Physiology, v.28, p.1-26, 2001.

SINGH, R.; SONI, S.K; KALRA, A. Synergy

between Glomus fasciculatum and a

beneficial Pseudomonas in reducing root

diseases and improving yield and forskolin

contente in Coleus forskohlii Briq. under 